\title{
Managing the mutations: academic misconduct in Australia, New Zealand and the UK
}

\author{
Melanie Birks ${ }^{{ }^{*}}$ (D) Jane Mills${ }^{2}$, Steph Allen ${ }^{3}$ and Stephen Tee ${ }^{4}$
}

\author{
* Correspondence: melanie.birks@ \\ jcu.edu.au \\ ${ }^{1}$ Head, Nursing and Midwifery, \\ College of Healthcare Sciences, \\ James Cook University, Townsville, \\ Queensland, Australia \\ Full list of author information is \\ available at the end of the article
}

\begin{abstract}
Academic misconduct is a problem of growing concern across the tertiary education sector. While plagiarism has been the most common form of academic misconduct, the advent of software programs to detect plagiarism has seen the problem of misconduct simply mutate. As universities attempt to function in an increasingly complex environment, the factors that contribute to academic misconduct are unlikely to be easily mitigated. A multiple case study approach examined how academic misconduct is perceived in universities in in Australia, New Zealand and the United Kingdom via interviews with academics and administrators. The findings show that academic misconduct is a systemic problem that manifests in various ways and requires similarly diverse approaches to management. Greater consistency in policies and procedures, including a focus on preventative education for both staff and students, is key to managing the mutations of academic misconduct that continue to plague the higher education sector globally.
\end{abstract}

Keywords: Assessment design, Academic misconduct, Cheating, Contract cheating, Essay mills, Plagiarism

\section{Background}

Internationally, academic misconduct continues to be an issue of increasing concern across the tertiary education sector. Historically, plagiarism has been the most common form of academic misconduct facing universities, however in the face of the development of software programs to detect plagiarism, the problem of misconduct simply mutates. This phenomenon can be seen with the emergence of paraphrasing programs and the growth of contract cheating in the form of bespoke assignment writing services provided by essay mills. Recent Australian research into contract cheating has shown three contributing factors: dissatisfaction in respect of teaching and learning experiences; speaking languages other than English at home; and a belief that there are numerous opportunities to cheat (Bretag et al. 2019a). Research into academic misconduct more broadly suggests that students engage in this practice for various social and structural reasons (Birks et al. 2018). As universities are required to function in an

(c) The Author(s). 2020 Open Access This article is licensed under a Creative Commons Attribution 4.0 International License, which permits use, sharing, adaptation, distribution and reproduction in any medium or format, as long as you give appropriate credit to the original author(s) and the source, provide a link to the Creative Commons licence, and indicate if changes were made. The images or other third party material in this article are included in the article's Creative Commons licence, unless indicated otherwise in a credit line to the material. If material is not included in the article's Creative Commons licence and your intended use is not permitted by statutory regulation or exceeds the permitted use, you will need to obtain permission directly from the copyright holder. To view a copy of this licence, visit http://creativecommons.org/licenses/by/4.0/. The Creative Commons Public Domain Dedication waiver (http://creativecommons.org/publicdomain/zero/1.0/) applies to the data made available in this article, unless otherwise stated in a credit line to the data. 
increasingly complex environment, the factors that contribute to academic misconduct are unlikely to be easily mitigated.

A review of the literature reveals considerable research in the area of academic misconduct (Awasthi 2019). In recent years, much of this work has focused on attitudes and perceptions towards academic misconduct (Ahmed 2018; Bašić et al. 2019; Finchilescu and Cooper 2018; Khoii and Atefi 2019; Lindahl and Grace 2018; Tindall and Curtis 2020), often in specific professional or disciplinary groups (Abdulghani et al. 2018; Birks et al. 2018; Brown et al. 2019; Cronan et al. 2018; Ewing et al. 2019; Kiekkas et al. 2020; Mohamed et al. 2018) or in respect of the influence of gender (Bokosmaty et al. 2019; Jereb et al. 2018; Zhang et al. 2018).

Factors that contribute to misconduct have also been investigated (Barbaranelli et al. 2018; Grira and Jaeck 2019; Moss et al. 2018; Yu et al. 2018), including cultural or international status (Ison 2018; James et al. 2019; Mahmud et al. 2019; Makarova 2019). While most current research in the area of student misconduct relates specifically to plagiarism, considerable work has been in respect of contract cheating (Bretag et al. 2020; Dawson and Sutherland-Smith 2018; Harper et al. 2019), particularly the motivation for student use (Amigud and Lancaster 2019a; Rundle et al. 2019; Sarwar et al. 2018), essay mill processes (Ellis et al. 2018; Foltýnek and Králíková 2018; Kaktiņš 2018; Lancaster 2020; Medway et al. 2018; Rowland et al. 2018) and the relationship with assessment design (Bretag et al. 2019b; Ellis et al. 2019; Harper et al. 2020).

The purpose of this study was to examine how academic misconduct is viewed and managed in universities in three countries, in a context where it is rapidly mutating. While previous research has examined approaches to managing misconduct (Pàmies et al. 2019; Royal et al. 2018), particularly in respect of prevention (Chauhan et al. 2018; Levine and Pazdernik 2018; Stoesz and Yudintseva 2018), detection (Amigud et al. 2018; Dawson et al. 2019; Foltýnek et al. 2019; Ison and Szathmary 2016; Shang 2019) and issues related to policy (Akbar and Picard 2019; de Maio et al. 2020; Taylor and Bicak 2019; Ullah 2019), there is limited knowledge of how the issue of student academic misconduct is currently viewed and managed by universities in the international context. This study aims to address that deficit.

\section{Method}

This research employed multiple case study design (Harrison et al. 2017) to investigate perceptions of academic misconduct and processes used to manage the problem in universities in Australia, New Zealand and the United Kingdom. Approval to conduct the study was obtained from Human Research Ethics Committees at the researchers' universities.

Participants were recruited via an email sent to Vice Chancellors asking them to nominate individuals with oversight of academic misconduct policy and procedures in their institution. Participation by universities and individuals was voluntary. Interviews were undertaken by video or telephone with staff from universities in Australia ( $n=14$, RR 36\%), New Zealand ( $n=4$, RR 50\%) and the United Kingdom $(n=10$, RR $8 \%)$ who occupied a mixture of academic and administrative positions. One participant failed to return a consent form and that data was therefore excluded. All interviews were individual, except for one case in the United Kingdom [UKP3] where two university employees were interviewed together.

A research assistant was employed to conduct the interviews to promote consistency in data collection. Interviews were structured using grounded theory methods, with a 
broad opening question used to commence discussion about academic misconduct in the participant's institution. From there, theoretical sampling was employed to direct and guide the discussion through areas of relevance as leads arose (Birks \& Mills, 2015). Duration of all interviews was less than 60 min.

Audio recordings were made of each interview and were professionally transcribed. Analysis of data from each location was undertaken by members of the research team in that country. Constant comparative analytical techniques were used to identify major themes that described the case in each country. A storyline was then developed commencing with the Australian data using techniques proposed by Birks and Mills (2019). Data from the New Zealand case and subsequently the UK case were synthesized to produce a storyline that reflected the multiple cases. This storyline presented in the following section presents a picture of how academic misconduct is perceived and managed in universities in Australia, New Zealand and the UK.

Findings

\section{A systemic problem}

Processes for the management of academic misconduct are enshrined in policies at most, but not all, universities. Some institutions have a specific policy for dealing with academic misconduct while others had this breach contained within other broader student conduct policies. Procedures for managing academic misconduct vary, with some institutions devolving responsibility to faculties or schools and others managing the process centrally. Serious and repeat breaches are often referred to a higher level committee or senior member of staff.

Participants identified problems with academic misconduct procedures that are largely related to the resource intensive nature of the associated processes, and inconsistencies in the implementation and application of policy. While some believed that academics located in the faculties would be best placed to manage academic misconduct, centralized processes were seen to increase consistency in decision making.

...every time a plagiarism case would go up she [Associate Dean Learning and Teaching] would take the side of the student and knock it and dismiss it; so that is something that you [are] very... conscious of and that's why ... if we change our decision making process I'd prefer it to be done perhaps through a panel decision ... or something that's not as close to the school. [AUP13]

Across the three countries, many participants indicated that their policies were under review at the time of this study so as to keep pace with the changing nature of the problem of academic misconduct.

I do have concerns that technology or modern students, however we want to phrase this, are continually changing ... and I'm not sure that our policies reflect that change well enough and I think ghost-writing is a prime example of that. [NZP2] 
All participants in Australia and New Zealand and most in the UK reported a reliance on plagiarism software for detection of academic misconduct, with a number of institutions mandating its use. While these text matching tools are largely considered valuable, a number of limitations were acknowledged, including variable utility and misuse of draft reports by students.

We use Turnitin, as a ... tool to support plagiarism investigations, but not in itself a plagiarism detection device. But we also do not let the students use it to check their own work, and I know some institutions do. Again, we debated this quite heavily... We want students to really understand what academic integrity means, and actually be focusing on creating a piece of work with academic integrity, rather than avoiding detection for plagiarism... [UKP5]

In Australia, inadequate staff capacity and capability to accurately interpret reports was raised as an issue, with many Australian participants assuming a predetermined tolerance level for the amount of similarity detected.

I think there is a common misconception that there is a magic number, that there is this magical percentage below which the work is fine. [AUP3]

Many participants also reported detection occurring through reports from whistle blowers. While it is not uncommon for third party contract cheating firms to report students to universities following a failure to pay, usually these whistle blowers are other students:

... we did indeed have a case last year ... where a [third year] student was dobbed in by an unhappy customer ... [another] student contacted the Pro-ViceChancellor's office ... and said, "I need to report to you that there is an essaywriting mill in operation on one of your campuses and this is the person who's involved." [NZP1]

Proven cases of academic misconduct are recorded on the student's file, and in some cases on the student's external transcript. Penalties available under academic misconduct policies vary considerably, and are imposed at the discretion of the delegated decision maker. Examples of penalties referred to include receiving a written warning, awarding a zero grade for an assessment or resubmission with a capped grade. Penalties increase with subsequent or more severe offences and include failure of a subject, suspension or expulsion from the university.

And we've never expelled somebody for a first offence. So it is only repeat offences and when there's been final year or post-graduate. As a Catholic institution, we like to give people the chance to repent. [UKP9]

While is it clear that students who engage in academic misconduct are in the minority, many participants have seen greater evidence of the problem in recent years. It was suggested, however, that this increase may be the result of improved vigilance. 
Nonetheless, there were concerns that the available data on academic misconduct represented the 'tip of the iceberg'. In Australia and the UK underreporting was considered an issue, with staff sometimes preferring to manage students informally or turn a blind eye, particularly where the process of reporting is considered 'burdensome'.

... they're overworked, and it's too hard, and they just think, 'I just can't, I've just got to let that one go through to the keeper' [AUP7]

Some discipline areas were identified as being more likely to report academic misconduct. In the UK, these include business, economics, maths, science and engineering. In Australia, disciplines such as health are more likely to report, while law is less likely to do so, as reporting could impact greatly on a student's future.

... they're very, very unwilling to breach a student at all for any circumstances because it means that they can't get a job, because it'll be on their record [AUP8]

Participants in Australia and the UK recognize that academic misconduct is a problem that is systemic. Rather than being the result of a single causative factor, academic misconduct is seen as multi-faceted, inclusive of organisational culture and systems. Some participants expressed concern that organisational change is contributing to the problem.

... this seems to be occurring because of this increasingly depersonalized teaching and learning environment. Students are feeling very disconnected from their institutions, from their learning journey, from educators. Nobody knows their name, they kind of feel like a number and they feel like nobody cares about them. So they don't feel a sense of commitment to a set of values that we tend to think represent the Academy. [AUP3]

Participants in these two countries indicated that concerns about academic misconduct cause staff to feel worried and disheartened. Varying staff attitudes and degrees of ownership in respect of the problem result in varying levels of vigilance. Dealing with the problem was considered to be draining, with a degree of despondency expressed by some participants.

... it makes you want to give up, doesn't it, that they're going to that sort of trouble? [AUP13]

\section{Students making bad decisions}

While some participants felt that academic misconduct is a problem not confined to any particular group, others felt that it is more likely in certain courses of study or cohorts. Academic misconduct is seen to be more prevalent in undergraduate than postgraduate students, and reflective of students' levels of maturity. Most participants identified it specifically as a problem with international students, although this was not always the case. 
... we find it's relatively proportionate ... domestic students are as likely as international students [AUP14]

... the breaches come from a range of students. ... but it is more towards international students first semester getting in the university. [NZP4]

International students are more likely to commit plagiarism particularly. And in certain cultures mimicking staff is seen as a good thing and respectful. [UKP3].

Participants in all countries described the varying nature of academic misconduct perpetrated by students. 'Bread and butter plagiarism' [AUP5] was identified as the most common form and was seen to span a continuum from unintentional poor referencing, to deliberately attempting to gain advantage.

I think we would be naïve to say that it is not plagiarism from the very soft inappropriate referencing to ... poor paraphrasing I suppose. The higher level is of course direct copying to attempt to make a gain from somebody else's work. It then gets more serious. [AUP11]

Often plagiarism takes the form of work previously submitted by other students, or direct copying from other sources.

The number one thing that we often hear is "I did this at the last minute. I was under severe time pressure, I was thinking I won't get it done on time, which is why I decided ... I'm just going to copy and paste something and just submit it." (NZP4)

In Australia, examples were given of students falsifying references to support an assignment.

... one of them was a health case dealing with indigenous wellbeing and to read it is just amazing. Unless you were reading it properly, you wouldn't have picked it up until you've read the reference list where it started talking about images of jelly fish and moon-landings, and the like. [AUP1]

While technology is useful in detecting academic misconduct, it was also identified as contributing to the problem. Where permitted, the repeated use of the draft checking facility in plagiarism software was seen to assist students by alerting them to problematic text that could then be reworked to avoid detection. More commonly, students are known to take existing work and 'spin' it through paraphrasing or translation software, or insert white characters as spaces in a document to fool plagiarism detection software. An additional level of concern relates to the use of content sharing sites, which have implications for both the student and university intellectual property.

This is a real problem because, if you're a student and you've got a high distinction for your assignment and somehow a third party external to the university finds out 
about that and they say, "Share your assignment," you know, an innocent student might well say, "Sure, I want to help other people ... " [NZP1]

'Good old-fashioned cheating' [AUP11] was also described by participants as occurring in invigilated examinations. Examples were given of students using unauthorized tools such as smart watches and mobile phones. Other examples included the use of ear pieces to receive information or notes hidden in laps or cached in advance in the toilet. One student used the label of a soft drink can to disguise notes. Talking, signalling, copying off another's exam paper and using "tattoo sleeves with algorithms and equations in them" [UKP7] were also identified as forms of cheating.

All participants in this study made reference to their concerns about third party cheating (contract cheating or ghost writing). The problem was described as complex and challenging, with a suggestion that it is on the rise, relative to other forms of academic misconduct.

... a number of ghost-writing assignments that we pick up I would hazard to guess

is probably a small percentage of those that are actually getting through [AUP11]

... it's almost impossible to prove, and I'm sure you'll probably hear this from everybody that you're talking to. [AUP2]

Concerns were raised about the strategies used by contract cheating firms (essay mills), including making common errors in a written piece to avoid detection, and the use of university branding to appear as legitimate enterprises. Contract cheating firms promise a product that will be undetectable by plagiarism software, however, the business model of these enterprises relies on quick turnaround and therefore rehashing previous work. Students may then find themselves with an allegation of misconduct, with guarantees offered by the third party of little comfort.

... it's interesting that ... most of them advertise that their product is plagiarismfree which is just about the most ironic thing that I can think of. [AUP3]

Third party cheating is not confined to essay writing, it also includes completion of assessments such as online quizzes and invigilated examinations.

$\ldots$ at a previous university I worked at, students were hiring other people to do their quizzes for them. And so impersonation [from] beginning to end. (AUP9)

... one of the ones that horrified me was that somebody sent us an email last year which was one of these websites talking about how to get around proctoring and invigilation ... by sending [the student] off to some other server ... (AUP13)

As with academic misconduct generally, third party cheating was seen to arise amongst a diverse range of students. International students are, however, considered to be more likely to use commercial services, with one participant expressing concern that agents recruiting students may be including assignment writing as part of the study package. 
Domestic students on the other hand are more likely to use informal arrangements, such as having their assignments written by family members. In such cases, a blurring of the lines was seen between providing reasonable assistance, such as tutoring, and having "unfair help" [AUP12]

... there is almost an implicit assumption that the students who will be availing themselves of the essay writing mill services will be international students. Now, we don't pay any attention, in my view, to the middle class student who lives at home whose mum or dad is an academic and says, "Here, let me help you with that assignment." And I can tell you, I have seen that many, many times. [NZP1]

But how one would actually define an essay mill and remember it is not just essay mills. You can have students, parents and siblings or course mates ... actually doing this as well. [UKP2].

Ultimately it is the use of contract cheating firms by students, rather than advertising or provision of the associated services by the firms themselves, that leads to an allegation of misconduct. In Australia and the UK, some participants suggested this situation is unjust.

... we're conscious that when we're dealing with students who have - we're dealing with the victims if you like ... well, they're perpetrators, of course, but they're victims as well in a way. And in some cases, it's almost as though they're groomed in a way by the [essay mill people]. [UKP4]

In addition to plagiarism and cheating, participants in Australia and New Zealand spoke about the rising incidence of falsified documents, such as medical certificates, transcripts, credit applications, English language test results and class attendance records. Research misconduct was also mentioned by a few participants, but largely in reference to it being handled differently to academic misconduct concerned with coursework.

Reasons for deciding to engage in academic misconduct were seen to be varied. Some participants felt that students lack an understanding of what is expected, do not take the requirements for integrity seriously or are simply 'lazy'. Others felt that the reasons were more complex and extended beyond 'just students behaving badly' [AUP3]. Examples were given in all three countries about the amount of pressure students were under, juggling study and other commitments, leading to a need to "make bad decisions" [AUP11].

... there might be some students who it's a bit of a moral decision but for most students it's kind of part of a series of very rational choices. Just not good ones, just not choices that demonstrate any integrity about the learning process. [AUP3]

... a lot of them are trying to prove something, not only to themselves, but to parents [UKP5] 
In some cases, it is "about survival" [AUP11].

They're not really motivated by their program or they're feeling an enormous amount of either financial pressure from their family to quickly get through their studies or just pressure to be successful in their studies. [AUP3]

When confronted with allegations of misconduct, students often deny any wrong doing, even in the face of overwhelming evidence. In Australia, participants gave examples of the excuses that students use when they do "fall on their sword" [AUP14], such as accidentally uploading the wrong file or simply running out of time. Others choose to justify their behavior.

... they create a narrative around what is acceptable - because we've got a terrible tutor or we don't want to do this subject or whatever it might be. [AUP9]

Participants also spoke about the increased reference to mental health problems in defence of alleged academic misconduct.

... we're seeing more and more students ... raise mental health issues ... in defence/mitigation. So ... we would take into account ... if someone was struggling $\ldots$ and it had been around the time that they had done this sort of behaviour, but we see it a lot. [AUP2]

\section{Managing the mutations}

Participants across the three countries discussed current and future ways of managing the mutating problem of academic misconduct. The multifaceted nature of the problem requires a multifaceted response.

... if we're going to have a concerted effort against academic integrity issues, we need everything from good education through good detection to appropriate methods of dealing with [it]... [AUP12]

Consistent with the suggestion that a lack of understanding of expectations is a significant contributing factor to students engaging in academic misconduct, many participants spoke about the importance of institutions reframing their approach to prevention and management as educative rather than punitive, particularly for minor offences. To this end, a number of universities use academic integrity modules as a preventative strategy. In many, but not all cases, completion of the module is compulsory. Stand-alone modules are considered less effective than academic integrity education entrenched in the curriculum.

... they embedded all this academic integrity education into the curriculum of those two courses and have halved their breaches in a year. [AUP3]

Participants felt that a key element of education is getting students to ask themselves whether academic misconduct is worth the trouble of attempting to cheat the system, particularly given the potential consequences. A number of participants spoke about 
increasing reports of students being blackmailed by contract cheating firms, reinforcing the need to raise students' awareness of the associated risks.

(The essay mills) contact the student and say, "Look, we've written all your essays for the past 12 months, so really your degree is not yours. And, if you want us to keep quiet about it, pay us $\mathrm{X}$ amount of money." [UKP10]

... it's a very treacherous area to be in as a student. I can imagine students with a professional dimension to their degree like accountancy here or medical or law ... I can imagine that getting into an extortion-type situation quite quickly. [NZP2]

Most participants spoke about the lack of preparedness of academics to detect and manage academic misconduct. Education for staff is seen as part of the solution, including in areas of identifying misconduct, interpreting evidence (including plagiarism software reports) and managing breaches in accordance with policy. The need to raise awareness in specific areas, such as contract cheating and the misuse of technology, was identified. Education of staff is currently addressed in various formal (such as training modules and workshops) and informal ways.

... we've found possibly more success in doing stuff in a more responsive way, as in when somebody has got an issue it becomes a teachable moment, which is very helpful. [AUP12]

Recycling of assessments year after year was also identified by a number of participants in all countries as a contributing factor to common types of academic misconduct.

In terms of assessment I think there's less control over that. Again staff understand that setting the same assignment year in, year out's probably not a good thing. [NZP2]

Examinations were not considered to offer any greater level of security.

... expecting students to sit exams in person may appear to be a way of foolproof guard against cheating but, particularly with international students who have nonEnglish names, an invigilator doesn't necessarily know who they've got in front of them. [NZP1]

Investment in assessment design is therefore considered a key factor in preventing academic misconduct. Designing assessment tasks that are authentic and personalized was seen as critical to addressing the problem.

In Australia and the UK, legislation was being proposed to criminalize contract cheating at the time of this study. This legislation was discussed by participants, who compared it with similar laws in the USA and New Zealand.

... it's about time that the government stepped in and said "look, this exchange is not okay" but it is unfair that the student is the only one who is penalized in the process. The writer should be penalized as well. [AUP3] 
... there's been some talk in the press about ... making the contract cheating essay mills illegal, which I completely support ... I would not be in favour of criminalising students though. [UKP9]

In Australia, however, concern was raised that focusing on the breaches rather than the broader circumstances may lead to a reduction in reporting.

... if we take too heavy-handed a regulatory approach to academic integrity, I'm worried that universities will think that reducing the number of breaches they have is the thing to focus on. And breaches can be reduced in a whole range of ways, not all of them good for learning and teaching or for integrity. [AUP3]

Participants across all three countries felt that with new approaches emerging, the problem of academic misconduct will continue to worsen into the future. Greater sophistication in contract cheating, use of artificial intelligence 'bots' to write assignments, and neuropharmacology to enhance memory were given as examples of what is expected, along with a growing incidence of student impersonation as the stakes increased. The situation was described as an "arms race" [AUP8; AUP11]. While staff would continue to rely on technology to detect academic misconduct, some students would also exploit technological advances to gain advantage and beat the system.

I think technology is the biggest challenge in two senses: in the ease with which students can actually breach AI and in terms of the difficulties in identifying it. [UKP2]

Increasingly advanced approaches to misconduct would require advanced approaches to detection and management including employing specialized staff and strategies. One participant suggested training up students to be experts at misconduct "like the hackers that the FBI hires" [AUP11]. Participants in Australia and the UK gave examples of technology being used to block access to commercial assignment writing sites and track students who attempted to view them.

We do block sites. A lot of the time, when they're essay mills, we will block them, but we can only block them on university campus computers ... so [on] their phone or off campus ... they can still access them. [UKP6].

\section{Discussion}

This study found considerable variation existed in the interpretation and application of policies and procedures used to manage academic misconduct. There are no nationally accepted standards for what constitutes academic misconduct, nor consistency in the application of penalties for students found guilty of cheating. Inconsistently applied penalties for academic misconduct increase students' appetite for risk and can result in them making the decision to cheat. Harper et al. (2019) argue that to disincentivize contract cheating, penalties need to be severe and include suspension from a student's course of study. 
Another novel finding from this study is that academic staff who are unconstrained by a centralized process for managing academic misconduct are strongly influenced by their professional context. In particular, law was identified as a discipline where academics are reluctant to prosecute misconduct for fear of terminating a student's progression to registration. This is of great concern, particularly in the UK, where law has been identified as particularly susceptible to essay mills (Lancaster 2020). Some academics, who may or may not have a centralized process to rely on for the investigation and management of student misconduct, choose to 'turn a blind eye' either because they feel emotionally exhausted by conflict, or because they feel their workload is already high enough without adding to it. The impost on workload of investigating and managing academic misconduct has been identified as a major barrier to policy implementation (Harper et al. 2019).

Relatively few studies have investigated academic misconduct from the perspective of university staff (Bretag et al. 2019b; Bretag et al. 2020; Harper et al. 2019; Lindahl and Grace 2018). Participants in this study provided a great deal of detail on the creative forms of academic misconduct they are experienced in managing. 'Bread and butter' plagiarism was the most commonly detected form of academic misconduct reported by participants. Although a base-level form of misconduct, this behavior shouldn't be discounted as an indicator of a student's propensity to continue to cheat during their program of study. A number of studies have found that students who have cheated successfully are at risk of normalizing this behavior (Moss et al. 2018; Tee and Curtis 2018). Document falsification was another form of misconduct raised as becoming increasingly prevalent. This trend is particularly concerning for disciplines where work integrated learning and similar authentic practice contexts rely on the integrity of such documents.

In terms of students defending their behavior, findings from this study are very similar to others conducted around the world (Birks et al. 2018; Kiekkas et al. 2020; Mahmud et al. 2019; Moss et al. 2018). What is different however is participants' perceptions of the increasing impact of mental health conditions on student's decisionmaking behavior. Given the increased rates of mental health and addiction globally, it is reasonable to hypothesis a relationship between students' mental health and academic misconduct. We recommend further research be undertaken to test this hypothesis and to better understand the decision-making process used by students in the context of academically dishonest behaviors.

In a fast changing context, managing the mutations of academic misconduct is a difficult task for the higher education sector. Overwhelmingly participants from all three countries included in this study agreed that education and support is the first line of defense against academic misconduct. While most spoke of academic integrity modules as important, there is clearly a need to include a stronger emphasis on values and the unethical behaviors of contract cheating companies. Importantly, academic staff need more continuing professional development on academic misconduct, the forms it can take, and methods to reduce the likelihood of cheating. A UK study of the content of higher education texts (Ransome and Newton 2018) found that academic integrity is poorly addressed and that contemporary issues such as contract cheating are not part of this discourse. In the current study, best practice assessment design was considered crucial to preventing academic misconduct, however there was an acknowledgement 
that cheating can occur no matter the form. This assertion is supported by Harper et al. (2020) who argue strongly against invigilated exams as a solution to academic misconduct, instead suggesting that written text or oral vivas both provided academics with greater opportunities to ensure the authenticity of a student's work. While authentic assessment is often referred to as the panacea for the problem of academic misconduct, Ellis et al. (2019) challenge that assertion. These authors further add that the resource intensive nature of true authentic assessment is likely unfeasible in the economic environment in which universities currently operate.

A number of participants argued that higher education institutions need to use artificial intelligence more proactively to combat the increasingly sophisticated methods that students use to cheat. This finding is supported by outcomes of a study on the use of Twitter to engage contract cheating services (Amigud 2019; Amigud and Lancaster 2019b). Those authors recommend the use of ethical bots that use the same technology as cheating service bots to raise students' awareness of the risks and consequences of using such a service. They also provide a longer term recommendation that higher education institutions begin to invest in deconstructing the business model of contract cheating services, and develop author validation technology to counter their actions. In the 'arms race' that is academic misconduct, we will likely find that such proactivity and innovation will be amongst the most important weapons in our armory.

\section{Conclusion}

Findings from this study highlight that the manifestations of academic misconduct and the response of institutions to the problem varies across the sector. Policies and procedures to address academic misconduct are inconsistently applied and so the problem remains systemic and unresolved. Whether through a lack of understanding or a response to personal and external pressures, students will continue to fall into the trap of misconduct as long as the factors that facilitate the behavior are not mitigated through an increase in academic integrity education and training. Collaborative approaches across the global higher education sector may offer a solution to the challenges ahead.

Abbreviations

UK: United Kingdom; USA: United States of America

Acknowledgements

Not applicable.

Authors' contributions

MB managed the project, conducted analysis of the Australian data, coordinated abstraction of findings, drafted sections of the final manuscript. JM conducted analysis of the New Zealand data and drafted sections of the final manuscript. SA and ST analysed the United Kingdom data and reviewed the final manuscript. All authors read and approved the final manuscript.

Authors' information

All authors are experienced academics and researchers with a particular interest in academic integrity in higher education.

Funding

No direct funding was received for this study.

Availability of data and materials

Conditions of ethics approval do not permit sharing of raw data as it is potentially identifiable. Data summaries, coding books and analysis maps are available from the corresponding author on request. 


\section{Author details}

${ }^{1}$ Head, Nursing and Midwifery, College of Healthcare Sciences, James Cook University, Townsville, Queensland, Australia. ${ }^{2}$ Dean and Head of School, Office of La Trobe Rural Health, Bendigo, Victoria, Australia. ${ }^{3}$ Lecturer, Faculty of Media and Communication, Bournemouth University, Bournemouth, UK. ${ }^{4}$ Executive Dean, Faculty of Health and Social Sciences, Bournemouth University, Bournemouth, UK.

Received: 23 July 2020 Accepted: 1 September 2020

Published online: 30 September 2020

\section{References}

Abdulghani HM, Haque S, Almusalam YA et al (2018) Self-reported cheating among medical students: an alarming finding in a cross-sectional study from Saudi Arabia. PLoS One 13(3):e0194963. https://doi.org/10.1371/journal.pone.0194963

Ahmed K (2018) Student perceptions of academic dishonesty in a private middle Eastern University. Higher Learning Res Communications 8(1):16-29. https://doi.org/10.18870/hlrc.v8i1.400

Akbar A, Picard M (2019) Understanding plagiarism in Indonesia from the lens of plagiarism policy: lessons for universities. Int J Educ Integr 15(1):1-17

Amigud A (2019) Cheaters on twitter: an analysis of engagement approaches of contract cheating services. Stud High Educ https://doi.org/10.1080/03075079.2018.1564258

Amigud A, Arnedo-Moreno J, Daradoumis T, Guerrero-Roldan A (2018) An integrative review of security and integrity strategies in an academic environment: current understanding and emerging perspectives. Comput Secur 76:50-70. https://doi.org/10.1016/j.cose.2018.02.021

Amigud A, Lancaster T (2019a) 246 reasons to cheat: an analysis of students' reasons for seeking to outsource academic work. Comput Educ 134:98-107

Amigud A, Lancaster T (2019b) I will pay someone to do my assignment: an analysis of market demand for contract cheating services on twitter. In: Assessment \& Evaluation in higher education, pp 1-13. https://doi.org/10.1080/02602938.2019. 1670780

Awasthi S (2019) Plagiarism and academic misconduct a systematic review. DESIDOC J Library Information Technol 39(2):94100. https://doi.org/10.14429/djitit39.2.13622

Barbaranelli C, Farnese ML, Tramontano C et al (2018) Machiavellian ways to academic cheating: a mediational and interactional model. Front Psychol 9:695. https://doi.org/10.3389/fpsyg.2018.00695.

Bašić Ž, Kružić I, Jerković I, Buljan I, Marušić A (2019) Attitudes and knowledge about plagiarism among university students: cross-sectional survey at the University of Split, Croatia. Sci Eng Ethics 25(5):1467-1483

Birks M, Mills, J (2015) Grounded theory: a practical guide (2nd ed). London: Sage.

Birks M, Mills J (2019) Rendering analysis through storyline the SAGE handbook of current developments in grounded theory, 3rd edn. Sage, London, pp 243-258

Birks M, Smithson J, Antney J, Zhao L, Burkot C (2018) Exploring the paradox: a cross-sectional study of academic dishonesty among Australian nursing students. Nurse Educ Today 65:96-101. https://doi.org/10.1016/j.nedt.2018.02.040

Bokosmaty S, Ehrich J, Eady MJ, Bell K (2019) Canadian university students' gendered attitudes toward plagiarism. J Furth High Educ 43(2):276-290

Bretag T, Harper R, Burton M et al (2019a) Contract cheating: a survey of Australian university students. Stud High Educ 44(11):1837-1856

Bretag T, Harper R, Burton M et al (2019b) Contract cheating and assessment design: exploring the relationship. Assess Eval High Educ 44(5):676-691. https://doi.org/10.1080/02602938.2018.1527892

Bretag T, Harper R, Rundle K et al (2020) Contract cheating in Australian higher education: a comparison of nonuniversity higher education providers and universities. Assess Eval High Educ 45(1):125-139. https://doi.org/10 1080/02602938.2019.1614146

Brown T, Bourke-Taylor H, Isbel S et al (2019) Establishing similarities and differences among the self-reported academic integrity of Australian occupational therapy undergraduate and graduate-entry Master's students. Open J Occupational Therapy 7(3):1-16

Chauhan PK, Wood E, Plummer T, Forsyth G (2018) Peer-based interventions on academic integrity: assessing immediate and long term learning. J Acad Ethics 16(2):133-149

Cronan TP, Mullins JK, Douglas DE (2018) Further understanding factors that explain freshman business students' academic integrity intention and behavior: plagiarism and sharing homework. J Bus Ethics 147(1):197-220

Dawson P, Sutherland-Smith W (2018) Can markers detect contract cheating? Results from a pilot study. Assess Eval High Educ 43(2):286-293

Dawson P, Sutherland-Smith W, Ricksen M (2019) Can software improve marker accuracy at detecting contract cheating? A pilot study of the Turnitin authorship investigate alpha. In: Assessment \& Evaluation in higher education, pp 1-10

de Maio C, Dixon K, Yeo S (2020) Responding to student plagiarism in Western Australian universities: the disconnect between policy and academic staff. J High Educ Policy Manag 42(1):102-116

Ellis C, van Haeringen K, Harper R et al (2019) Does authentic assessment assure academic integrity? Evidence from contract cheating data. Higher Educ Res Dev:1-16. https://doi.org/10.1080/07294360.2019.1680956

Ellis C, Zucker I, Randall D (2018) The infernal business of contract cheating: understanding the business processes and models of academic custom writing sites. Int J Educ Integr 14:1

Ewing $H$, Mathieson $K$, Anast A, Roehling T (2019) Student and faculty perceptions of plagiarism in health sciences education. J Furth High Educ 43(1):79-88. https://doi.org/10.1080/0309877X.2017.1356913

Finchilescu G, Cooper A (2018) Perceptions of academic dishonesty in a south African university: a Q-methodology approach Ethics Behav 28:284-301

Foltýnek T, Králíková V (2018) Analysis of the contract cheating market in Czechia. Int J Educ Integr 14:1-15

Foltýnek T, Meuschke N, Gipp B (2019) Academic plagiarism detection: a systematic literature review. ACM Computing Surveys (CSUR) 52(6):1-42 
Grira J, Jaeck L (2019) Rationality and Students' misconduct at university: empirical evidence and policy implications. Int Educ Stud 12(3):10-23

Harper R, Bretag T, Ellis C et al (2019) Contract cheating: a survey of Australian university staff. Stud High Educ 44(11):18571873. https://doi.org/10.1080/03075079.2018.1462789

Harper R, Bretag T, Rundle K (2020) Detecting contract cheating: examining the role of assessment type. Higher Educ Res Dev:1-16. https://doi.org/10.1080/07294360.2020.1724899

Harrison H, Birks M, Franklin R, Mills J (2017) Case study research: foundations and methodological orientations. FQS Forum 18(1): Art. 19. http://nbn-resolving.de/urn:nbn:de:0114-fas1701195

Ison DC (2018) An empirical analysis of differences in plagiarism among world cultures. J High Educ Policy Manag 40(4):291-304

Ison DC, Szathmary KJ (2016) Assessing academic integrity using SafeAssign plagiarism detection software. Collegiate Aviation Rev Int 34(1):35-47. https://doi.org/10.22488/okstate.18.100466

James MX, Miller GJ, Wyckoff TW (2019) Comprehending the cultural causes of English writing plagiarism in Chinese students at a Western-style university. J Bus Ethics 154(3):631-642

Jereb E, Urh M, Jerebic J, Šprajc P (2018) Gender differences and the awareness of plagiarism in higher education. Soc Psychol Educ 21(2):409-426

Kaktinš L (2018) Contract cheating advertisements: what they tell us about international students' attitudes to academic integrity. Ethics Educ 13(2):268-284

Khoii R, Atefi M (2019) Perceptions of plagiarism in academic settings: are university students and professors in the same boat? Literacy Information Comput Educ J 10(3):3232-3237

Kiekkas P, Michalopoulos E, Stefanopoulos N et al (2020) Reasons for academic dishonesty during examinations among nursing students: cross-sectional survey. Nurse Educ Today 86:104314. https://doi.org/10.1016/j.nedt.2019.104314

Lancaster T (2020) Academic discipline integration by contract cheating services and essay Mills. J Acad Ethics. https://doi. org/10.1007/s10805-019-09357-x

Levine J, Pazdernik V (2018) Evaluation of a four-prong anti-plagiarism program and the incidence of plagiarism: a five-year retrospective study. Assess Eval High Educ 43(7):1094-1105

Lindahl JF, Grace D (2018) Students' and supervisors' knowledge and attitudes regarding plagiarism and referencing. Res Integr Peer Rev 3. https://doi.org/10.1186/s41073-018-0054-2

Mahmud S, Bretag T, Foltýnek T (2019) Students' perceptions of plagiarism policy in higher education: a comparison of the United Kingdom, Czechia, Poland and Romania. J Acad Ethics 17(3):271-289. https://doi.org/10.1007/s10805-018-9319-0

Makarova M (2019) Factors of academic misconduct in a cross-cultural perspective and the role of integrity systems. J Acad Ethics 17(1):51-71. https://doi.org/10.1007/s10805-019-9323-z

Medway D, Roper S, Gillooly L (2018) Contract cheating in UK higher education: a covert investigation of essay mills. Br Educ Res J 44(3):393-418. https://doi.org/10.1002/berj.3335

Mohamed ME, Mohy N, Salah S (2018) Perceptions of undergraduate pharmacy students on plagiarism in three major public universities in Egypt. Account Res 25(2):109-124

Moss S, White B, Lee J (2018) A systematic review into the psychological causes and correlates of plagiarism. Ethics Behav 28(4):261-283. https://doi.org/10.1080/10508422.2017.1341837

Pàmies MM, Valverde M, Cross C (2019) Organising research on university student plagiarism: a process approach. In: Assessment \& Evaluation in higher education, pp 1-18

Ransome J, Newton PM (2018) Are we educating educators about academic integrity? A study of UK higher education textbooks. Assess Eval High Educ 43(1):126-137. https://doi.org/10.1080/02602938.2017.1300636

Rowland S, Slade C, Wong K-S, Whiting B (2018) 'Just turn to us': the persuasive features of contract cheating websites. Assess Eval High Educ 43(4):652-665

Royal KD, Neel JA, Munana KR, Flammer K (2018) Using a modified bookmark procedure to help identify reasonable consequences for academic integrity violations. J Vet Med Educ 45(1):43-50. https://doi.org/10.3138/jvme.0816-126r2

Rundle K, Curtis GJ, Clare J (2019) Why students do not engage in contract cheating. Front Psychol 10. https://doi.org/10. 3389/fpsyg.2019.02229

Sarwar S, Idris ZM, Ali SM (2018) Paid academic writing services: a perceptional study of business students. Int J Exper Learning Case Studies 3(1):73-83

Shang H-F (2019) An investigation of plagiarism software use and awareness training on English as a foreign language (EFL) students. J Comput High Educ 31(1):105-120

Stoesz BM, Yudintseva A (2018) Effectiveness of tutorials for promoting educational integrity: a synthesis paper. Int J Educ Integr 14(6). https://doi.org/10.1007/s40979-018-0030-0

Taylor ZW, Bicak I (2019) Academic honesty, linguistic dishonesty: analyzing the readability and translation of academic integrity and honesty policies at US postsecondary institutions. J Acad Ethics 17(1):1-15

Tee S, Curtis K (2018) Academic misconduct - helping students retain their moral compass. Nurse Educ Today 61:153-154. https://doi.org/10.1016/j.nedt.2017.11.030

Tindall IK, Curtis GJ (2020) Negative emotionality predicts attitudes toward plagiarism. J Acad Ethics 18(1):89-102

Ullah I (2019) Letting the cheaters always win: the scantiness of public policy to curb cheating in the academic settings. J Bus Econ 11(1):1-20

Yu H, Glanzer PL, Johnson BR, Sriram R, Moore B (2018) Why college students cheat: a conceptual model of five factors. Rev High Educ 41(4):549-576. https://doi.org/10.1353/rhe.2018.0025

Zhang Y, Yin H, Zheng L (2018) Investigating academic dishonesty among Chinese undergraduate students: does gender matter? Assess Eval High Educ 43(5):812-826

\section{Publisher's Note}

Springer Nature remains neutral with regard to jurisdictional claims in published maps and institutional affiliations. 